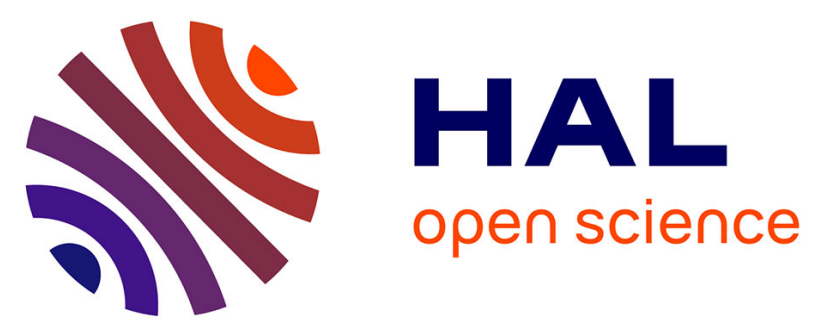

\title{
Delayed Pulmonary Arterial Hypertension in Relation to Pulmonary Damage Score after Pneumonectomy under Protective Ventilation: Experimental Study
} Jean-Philippe Berthet, Olivier Attard, Laurence Solovei, Arnaud Bourdin, Isabelle Serre, Nicolas Molinari, Sylvain Richard, Stefan Matecki

\section{To cite this version:}

Jean-Philippe Berthet, Olivier Attard, Laurence Solovei, Arnaud Bourdin, Isabelle Serre, et al.. Delayed Pulmonary Arterial Hypertension in Relation to Pulmonary Damage Score after Pneumonectomy under Protective Ventilation: Experimental Study. European Surgical Research, 2013, 10.1159/000357058 . hal-02544817

\section{HAL Id: hal-02544817 \\ https://hal.umontpellier.fr/hal-02544817}

Submitted on 16 Apr 2020

HAL is a multi-disciplinary open access archive for the deposit and dissemination of scientific research documents, whether they are published or not. The documents may come from teaching and research institutions in France or abroad, or from public or private research centers.
L'archive ouverte pluridisciplinaire HAL, est destinée au dépôt et à la diffusion de documents scientifiques de niveau recherche, publiés ou non, émanant des établissements d'enseignement et de recherche français ou étrangers, des laboratoires publics ou privés. 


\title{
Delayed Pulmonary Arterial Hypertension in Relation to Pulmonary Damage Score after Pneumonectomy under Protective Ventilation: Experimental Study
}

\author{
Jean-Philippe Berthet ${ }^{a, b} \quad$ Olivier Attard ${ }^{a} \quad$ Laurence Solovei $^{a}$ \\ Arnaud Bourdin $^{b}$ Isabelle Serre ${ }^{a}$ Nicolas Molinari ${ }^{b}$ Sylvain Richard ${ }^{b}$ \\ Stefan Matecki ${ }^{\mathrm{b}}$ \\ ${ }^{a}$ Division of Thoracic Surgery and Division of Cardiothoracic Anesthesia and Critical Care \\ Medicine, Hospital Arnaud de Villeneuve, and b U1046, INSERM, Université Montpellier 1, \\ Université Montpellier 2, Montpellier, France
}

\section{Key Words}

Lung injury · Pneumonectomy · Pulmonary artery hypertension · Postpneumonectomy edema

\begin{abstract}
Objective: To characterize pulmonary hemodynamic changes in relation to lung injury at 2 time points [48 $\mathrm{h}(\mathrm{H} 48)$ and $168 \mathrm{~h}(\mathrm{H} 168)]$ after pneumonectomy under intraoperative protective ventilation in order to improve postpneumonectomy pulmonary edema (PPE) prevention. Method: Fifteen pigs $(25 \pm 1.9 \mathrm{~kg}$ ) were randomly allocated to nonsurgical (control, $n=5)$ and surgical (H48 and $\mathrm{H} 168$ ) groups. A left pneumonectomy under volume-controlled one-lung ventilation (OLV) (low tidal volume, positive end-expiratory pressure $=4 \mathrm{~cm} \mathrm{H} \mathrm{H}_{2} \mathrm{O}$, inspired oxygen fraction $=50 \%$ ) was performed in surgical animals. Mean pulmonary artery pressure (MPAP) and pulmonary artery occlusion pressure were recorded. Pulmonary vascular resistance (PVR) was calculated. Pulmonary damage score (PDS) and bronchoalveolar albumin level were evaluated. Data were collected after induction (T0), after OLV (T1), after left pneumonectomy (T2), and at H48 or H168 (T3). Results: Pneumonectomy caused precapillary pulmonary arterial hypertension (PAH) measured at T3 H48 $(36.2 \pm 3.67 \mathrm{~mm} \mathrm{Hg})$. PAH was delayed temporarily (both after OLV and after pneumonectomy) $(p<0.001)$, and linked with PVR $(r=0.93 ; p<0.05)$. PDS and bronchoalveolar albumin level varied with MPAP $(r=0.76$; $p<0.001$ and $r=0.55 ; p<0.05)$. Conclusion: Given that PAH is delayed and related to PVR increase, indicating secondary pulmonary vascular bed adaptation limits, pharmacological treatment should focus on a delayed failure in pulmonary capacitance in patients at risk of PPE.
\end{abstract}




\section{Introduction}

Postpneumonectomy pulmonary edema (PPE) is a highly challenging respiratory disorder for thoracic surgeons and anesthesiologists to detect and treat. Once it develops, mortality ranges from 53 to $74 \%$ [1], and PPE has a major impact on health resources, accounting for much of the length of stay in intensive care units after major pulmonary resection (MPR) [1, 2]. The definition of PPE is variable and overlaps with 'acute lung injury' [3]. Incidence fluctuates slightly, from 4 to $15 \%$ depending on the definition used.

The physiopathology of PPE is poorly defined and has a multifactorial etiology [4]. Hemodynamic disorders have a central role: perioperative fluid overload, increased pulmonary capillary pressure [5], lung lymphatics interruption [4-7], right ventricular dysfunction [8], and pulmonary endothelial damage [9] have been implicated. It has been suggested that after cross-clamping the arterial supply of the lung to be resected, increased blood flow in the remaining lung may induce an immediate rise in pulmonary capillary pressures and immediate plasma translocation to interstitial space $[4,10]$.

The friction of increased blood flow on pulmonary endothelium, called vascular shear stress [11], which activates endothelial-derived vasoactive substances [12, 13], has been suggested as another participating mechanism. Mechanical one-lung ventilation (OLV) also plays a combined role in pulmonary injury $[5,6]$ through capillary external compression and alveolar injury secondary to barotraumatism and volotraumatism related to high tidal volume $\left(\mathrm{V}_{\mathrm{t}}\right)$. However, these explanations conflict with clinical reality, given that acute onset of hypoxemia and respiratory failure in PPE occur 48 to $72 \mathrm{~h}$ [1] after MPR.

Protective OLV strategies partially decreased PPE incidence [11, 14-16]. Modulation of cellular pathways involved in endothelial response to shear stress could be an additional promising tool to prevent PPE, provided that pulmonary hemodynamic changes after MPR using a low-insufflation $\mathrm{V}_{\mathrm{t}}$ are considered in preclinical models.

Our study objective was to characterize pulmonary hemodynamic deterioration at different time points after MPR [48 h (H48) and $168 \mathrm{~h}$ (H168)] under protective OLV, in relation to a pulmonary damage score (PDS). We chose a large-animal model that our research team masters very successfully [17].

\section{Materials and Methods}

Fifteen female large white pigs (mean weight, $25 \pm 1.9 \mathrm{~kg}$ ) were randomized to 3 equal groups: 2 experimental (H48 and H168) and 1 control group. The study protocol was approved by the local experimental laboratory ethics committee (F-C34-172-22). All animal care complied with the 'Principles of Laboratory Animal Care' of the National Society for Medical Research and the 'Guide for the Care and Use of Laboratory Animals' from the Institute of Laboratory Animal Resources (National Institutes of Health publication No. 86-23, revised 1985).

\section{Anesthesia and Mechanical Ventilation}

Animals were premedicated with an intramuscular injection of ketamine $(15 \mathrm{mg} / \mathrm{kg})$ and xylazine $(2$ $\mathrm{mg} / \mathrm{kg}$ ). Anesthesia was induced with intravenous thiopental $(10 \mathrm{mg} / \mathrm{kg})$. After endotracheal intubation using a single lumen device, sufentanil maintained anesthesia with continuous intravenous injection of propofol $(10 \mathrm{mg} / \mathrm{kg} / \mathrm{h})$. Neuromuscular blockade was obtained with vecuronium $(0.2 \mathrm{mg} / \mathrm{kg}$ after induction and $0.04 \mathrm{mg} / \mathrm{kg}$ every half hour). We used a transdermal fentanyl patch $(1 \mu \mathrm{g} / \mathrm{kg})$ for postoperative analgesia. Total preoperative fluid administered was $5 \mathrm{ml} / \mathrm{kg}^{-1} / \mathrm{h}^{-1}$. Cefamandole (50-60 mg/kg) was used for antibiotic prophylaxis. Mechanical ventilation used a Servo Ventilator 900D (Siemens-Elema AB, Solna, Sweden), applying the following parameters:

(a) During volume-controlled double-lung ventilation, animals received conventional (assisted support) ventilation at a $\mathrm{V}_{\mathrm{t}}$ of $7 \mathrm{ml} / \mathrm{kg}$ with positive end-expiratory pressure (PEEP) between 3 and $4 \mathrm{~cm} \mathrm{H}_{2} \mathrm{O}$. Respi- 
ratory rate (RR) was 20 cycles/min, with carbon dioxide tension $\left(\mathrm{PaCO}_{2}\right)<40 \mathrm{~mm} \mathrm{Hg}$, and inspired oxygen fraction $\left(\mathrm{FiO}_{2}\right)$ was $50 \%$ with pulse oxygen saturation $\left(\mathrm{SpO}_{2}\right)$ maintained between 96 and $99 \%$.

(b) During OLV, after surgical cross-clamping of the left main bronchus and until extubation, we maintained the ventilatory parameters used in double-lung ventilation.

\section{Hemodynamic and Ventilatory Parameter Monitoring}

(a) Electrocardiography, heart rate, and temperature were continuously recorded. An arterial catheter (Arrow Arterial Catheterization Kit, 20 gauge) was inserted into the right carotid artery to monitor systemic pressure and arterial blood gases.

(b) Inspired and expired gases $\left(\mathrm{O}_{2}\right.$ and $\left.\mathrm{CO}_{2}\right), \mathrm{RR}, \mathrm{V}_{\mathrm{t}}$, and plateau pressure were continuously monitored.

(c) A Swan-Ganz catheter (741HF75, Edwards Lifesciences, Irvine, Calif., USA) was inserted by an 8 -french introducer into the right jugular vein. Its tip was positioned in the pulmonary artery, guided by pressure traces. These catheters were connected to individual pressure transducers and a Philips monitor (Philips Healthcare, Andover, Mass., USA) to measure at end-expiration (after zeroing) the mean pulmonary artery pressure (MPAP), right atrial pressure, and pulmonary artery occlusive pressure (PAOP). The PAOP was obtained after pulmonary artery occlusion, induced by intermittent inflation of the catheter balloon. With a Vigilance monitor (Edwards Lifesciences), cardiac output was determined by thermodilution (bolus of $12 \mathrm{ml}$ of $4^{\circ} \mathrm{C}$ Ringer's solution injected into the superior vena cava). Pulmonary vascular resistance (PVR) was then calculated.

The data presented correspond to the average of 3 measurements obtained with subjects in standard lateral position after disconnecting the respirator from the endotracheal tube at end-expiration.

\section{Left Pneumonectomy}

Animals were positioned on the right side and left muscle-sparing thoracotomy was performed. Selective intubation was technically unreliable because of the frequent presence of tracheal bronchus for the right upper lobe in our pigs. Therefore, we began the surgical procedure by cross-clamping the left main bronchus for $60 \mathrm{~min}$, modeled after OLV which is generally required for pneumonectomy surgery in humans.

Left pneumonectomy was performed using a procedure similar to surgery in humans. After dissection of the pulmonary artery and veins and left superior pulmonary vein ligation, the left pulmonary artery and left inferior pulmonary vein were divided. The left main bronchus was divided with an automatic device. At the end of surgery, the tracheal tube was removed and animals were transferred to a recovery room.

At the end of the protocol (H48 or H168), right pneumonectomy was performed in a single-step procedure and was sampled to obtain histological values for vascular and alveolar morphology.

\section{Experimental Protocol}

Surgical Animals

The 10 surgical animals were randomly allocated to 2 time points of sacrifice after left pneumonectomy: the H48 group ( $n=5)$ and the H168 group ( $n=5)$. All measurements were done after a stabilization period without changes in ventilatory or hemodynamic parameters. The experimental design is diagrammed in figure 1. At each time point, the same set of measurements was performed, including ventilatory parameters and systemic and pulmonary hemodynamic data.

The first day (day 0) included 3 time points (T0, T1, and T2). At T0, individual baseline values were obtained (animals were positioned on the right side). A thoracic approach was then performed and the left main bronchus was cross-clamped. The T1 values were obtained after $60 \mathrm{~min}$ of OLV. Left pneumonectomy was performed and $\mathrm{T} 2$ values obtained after $60 \mathrm{~min}$.

At the end of day 0, pigs were awakened and weaned from invasive ventilation. The next set of measurements (T3) was taken on the second (T3 H48) or seventh (T3 H168) postoperative day, according to experimental group. A right thoracic approach and right pneumonectomy were performed after T3.

At all time points, we measured the following parameters: (a) central temperature and weight; (b) ventilation $\left(\mathrm{FiO}_{2}, \mathrm{~V}_{\mathrm{t}}, \mathrm{RR}\right.$, and PEEP); (c) systemic hemodynamic data, and (d) pulmonary hemodynamic data (cardiac output, MPAP, PVR, and PAOP) and arterial blood gas.

Nonsurgical Animals

Five control animals underwent only the T0 measurements. 


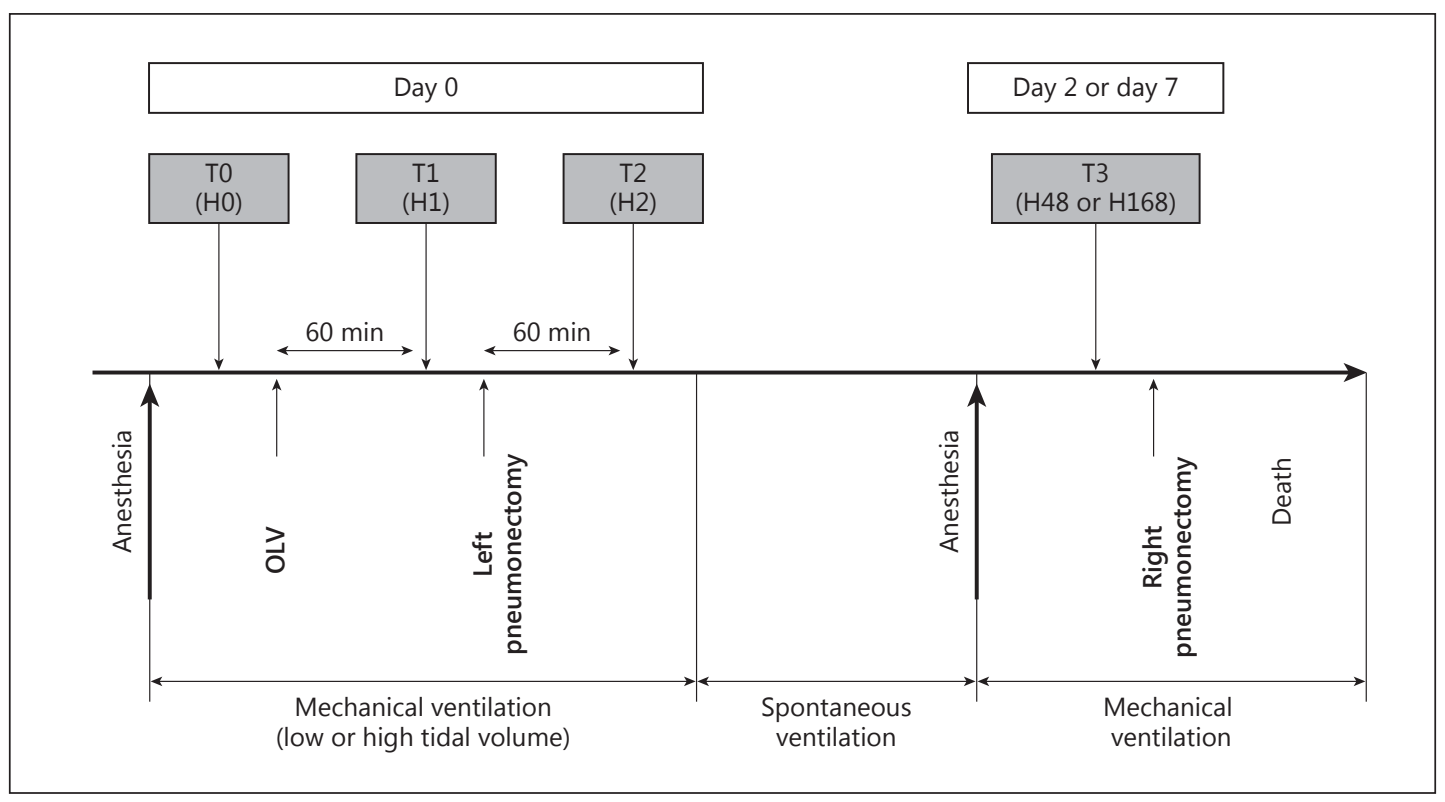

Fig. 1. Schematic representation of experimental design showing time points and chronology of measurements and samples.

\section{Histopathology}

A lung tissue biopsy was performed at T0 of the left lung using an automatic device, at T2 of the left lung after left pneumonectomy, and at T3 H48 or T3 H168 of the right lung to determine PDS regarding specific lesions.

Immediately after the thoracic approach and before any lung manipulation, left upper lobe tissue was sampled to obtain individual baseline histological values for vascular and alveolar morphology. At T2, the left lung was drained of blood and delivered for histopathologic analysis. The lung was inflated and gravity-filled through the main bronchus to the main bronchial margin with $10 \%$ formalin before division (standardized protocol, presented below). At T3, the right lung was similarly prepared. Both lungs were fixed within $1 \mathrm{~h}$ of explantation.

\section{Standardized Protocol for Division}

Blocks of lung tissue $\left(2 \mathrm{~cm}^{3}\right)$ were harvested from the lobes at 2 representative locations: peripheral and central. Samples were fixed, embedded in paraffin, sectioned (2- to 3- $\mu \mathrm{m}$ slices), and stained with hematoxylin and eosin for light-microscopic analysis. Blinded pathologists evaluated the samples using a modification of a previously published scoring system [18]. Lung injury characteristics were estimated by light microscopy using magnifications of $\times 40, \times 100$, and $\times 400$. Two sections of each upper and lower lobe were analyzed in separate nonoverlapping fields of view for the following characteristics: interstitial edema, inflammatory infiltration, and alveolar overdistension. Values from 0 to 3 were assigned to represent severity: $0=$ normal appearance; 1 = slight effect; $2=$ intermediate effect, and $3=$ severe effect. The extent of damage in each sector was described as follows: $0=$ no damage; $1=$ up to $25 \%$ damage; $2=25-50 \%$ damage; $3=50-75 \%$ damage; $4=75 \%$ to almost complete damage, and $5=$ complete damage. For each feature evaluated, severity was multiplied by extent to calculate a PDS ranging from 0 to 15 . Values for all sectors per lung were averaged.

\section{Bronchoalveolar Lavage Albumin Level}

Bronchoalveolar lavage (BAL) albumin level was assessed using three 50-ml aliquots of sterile 0.9\% saline solution at $37^{\circ} \mathrm{C}$ infused through a pediatric fiberoptic bronchoscope in the anterior segment of the lower lobe and then withdrawn by gentle aspiration. BAL albumin level was measured at T0, T2, T3 H48, and T3 H168 in the right lung without handling the first aliquot in the unconcentrated BAL using commercially available ELISA kits (Genzyme, Cambridge, Mass., USA). 
Table 1. Ventilatory parameters (plateau pressure, $V_{t}$, PEEP, and RR), systemic hemodynamics (HR and MAP) and blood gas exchange $\left(\mathrm{SvO}_{2}\right.$ and $\left.\mathrm{EtCO}_{2}\right)$ at each time point

\begin{tabular}{|c|c|c|c|c|c|}
\hline \multirow{2}{*}{$\begin{array}{l}\text { Ventilatory } \\
\text { parameters }\end{array}$} & \multicolumn{5}{|l|}{ Time points } \\
\hline & T0 & $\mathrm{T} 1$ & $\mathrm{~T} 2$ & T3 H48 & Т3 H168 \\
\hline PEEP, $\mathrm{cm} \mathrm{H}_{2} \mathrm{O}$ & 4 & 4 & 4 & 4 & 4 \\
\hline $\mathrm{V}_{\mathrm{t}}, \mathrm{ml} / \mathrm{kg}$ & $7.8 \pm 0.39$ & $8.2 \pm 0.72$ & $8.1 \pm 0.52$ & $7.8 \pm 0.41$ & $8.2 \pm 0.46$ \\
\hline $\mathrm{HR}$ & $102.2 \pm 26.1$ & $77.8 \pm 16.4^{*}$ & $74.0 \pm 10.6^{*}$ & $107.6 \pm 16.5$ & $105.2 \pm 20.3$ \\
\hline MAP, mm Hg & $89.9 \pm 14.7$ & $94.4 \pm 11.2$ & $90.7 \pm 8.5$ & $99.0 \pm 11.9$ & $94.6 \pm 17.3$ \\
\hline $\mathrm{SvO}_{2}$ & $98.3 \pm 0.9$ & $98.3 \pm 1.0$ & $97.8 \pm 0.9$ & $98.2 \pm 1.3$ & $97.4 \pm 1.1$ \\
\hline $\mathrm{EtCO}_{2}$ & $35.6 \pm 1.9$ & $36.3 \pm 5.8$ & $39.8 \pm 4.3$ & $44.0 \pm 10.1$ & $45.0 \pm 11.6$ \\
\hline
\end{tabular}

Data are presented as means \pm standard deviation. $\mathrm{HR}=$ Heart rate; $\mathrm{MAP}=$ mean artery pressure; $\mathrm{SvO}_{2}=$ venous oxygen saturation of the blood; $\mathrm{EtCO}_{2}=$ expired $\mathrm{CO}_{2}{ }^{*} \mathrm{p}<0.05$.

\section{Statistical Analysis}

The intent was to examine key values for changes in the pulmonary hemodynamic profile and to characterize lung injuries. Consequently, the sample size was not based on a prespecified power. Data were computerized and analyzed with Minitab statistical software, choosing an adequate test for small sets of quantitative data. We first analyzed population distribution for each value separately with a sensitive Anderson-Darling normality test. All values are reported as means \pm standard deviation. After formally testing normal distribution, we compared values of hemodynamic data at different time points using a paired $\mathrm{t}$ test. We tested the null hypothesis with a $0.05 \alpha$ level of significance and performed linear regression analysis to evaluate the correlation between hemodynamic pulmonary values, PDS, and BAL.

\section{Results}

At T0, the surgical and nonsurgical groups were strictly identical in their systemic and pulmonary hemodynamics and histological profile.

\section{Animal Model Tolerance, Systemic Hemodynamic Values}

The surgical groups were similar in weight $(25.2 \pm 1.8$ vs. $25.3 \pm 1.4 \mathrm{~kg}, \mathrm{p}=0.92)$ and mean duration of surgical procedure $(133 \pm 27.2 \mathrm{vs} .139 \pm 16.6, p=0.55)$. Both groups received a similar mean volume of intraoperative saline infusion (346 $\pm 76 \mathrm{vs}$. $323 \pm 65 \mathrm{ml}, \mathrm{p}=0.66$ ). No changes in ventilatory parameters were needed to maintain constant saturation, and thus OLV was considered well tolerated. Table 1 reports the mean values and standard deviation of ventilatory parameters ( $\mathrm{V}_{\mathrm{t}}, \mathrm{PEEP}$, and $\mathrm{RR}$ ), systemic hemodynamics (heart rate and cardiac output), and blood gas exchange.

No statistical differences were observed between groups and time points, except for mean heart rate at T1 and T2, and mean cardiac output at T3 H168 (table 1). Mean cardiac output at T3 H168 was significantly higher than mean cardiac output at other time points $(\mathrm{p}=0.01)$. No statistical differences were observed in arterial oxygen tension $\left(\mathrm{PaO}_{2}\right) / \mathrm{FiO}_{2}$ $(\mathrm{mm} \mathrm{Hg})$ at T3 H48 (323 $\pm 40, \mathrm{p}=0.66)$ and T3 H168 (372 $\pm 85, \mathrm{p}=0.85)$ compared to T1 $(396 \pm 78)$.

\section{Pulmonary Hemodynamic Values}

MPAP and PVR values were normally distributed (table 2). At $48 \mathrm{~h}$ after left pneumonectomy (T3 H48), PVR was increased compared to baseline T0 (485.6 \pm 139.6 vs. $258.9 \pm$ $71.1 \mathrm{dyn} \cdot \mathrm{s} \cdot \mathrm{cm}^{-5} \cdot \mathrm{m}^{-2}, \mathrm{p}=0.014$; fig. $2 \mathrm{a}$ ). On the seventh postoperative day (T3 H168), a 
Table 2. Pulmonary hemodynamic values: normal distribution of values according to the Anderson-Darling normality test allowed a comparison of mean values at different time points

\begin{tabular}{lccccc}
\hline $\begin{array}{l}\text { Pulmonary } \\
\text { hemodynamic } \\
\text { values }\end{array}$ & Time points & & & \\
\cline { 2 - 6 } & T0 & T1 & T2 & T3 H48 & T3 H168 \\
\hline CO, l/min & $3.1 \pm 0.7$ & $2.7 \pm 0.4$ & $2.9 \pm 0.6$ & $3.5 \pm 0.7$ & $3.7 \pm 0.4^{* *}$ \\
RAP, mm Hg & $8.0 \pm 3.6$ & $8.0 \pm 3.4$ & $8.0 \pm 3.3$ & $11.6 \pm 8.1$ & $10.0 \pm 3.9$ \\
PAOP, mm Hg & $10.8 \pm 1.6$ & $12.8 \pm 2.2$ & $12.4 \pm 2.6$ & $12.4 \pm 5.3$ & $11.2 \pm 3.2$ \\
PVR, dyn & $258.9 \pm 71.1$ & $311.6 \pm 81.9$ & $285.5 \pm 77.1$ & $485.6 \pm 139.6^{*}$ & $259.4 \pm 38.7^{* *}$ \\
MPAP, mm Hg & $20.9 \pm 2.3$ & $22.5 \pm 3.6$ & $22 \pm 4.4$ & $36 \pm 3.6^{*}$ & $24.4 \pm 3.8^{* *}$ \\
\hline
\end{tabular}

Data are presented as means \pm standard deviation. $\mathrm{CO}=$ Cardiac output; RAP $=$ right atrial pressure. ${ }^{*} \mathrm{p}<$ $0.05 ; *$ p $<0.001$.

significantly lower PVR value was observed compared to the second postoperative day (T3 H48) values ( $259.4 \pm 38.7$ vs. $\left.485.6 \pm 139.6 \mathrm{dyn} \cdot \mathrm{s} \cdot \mathrm{cm}^{-5} \cdot \mathrm{m}^{-2}, \mathrm{p}=0.022\right)$, which returned to baseline values. Similar changes in MPAP were observed between T0 and T3 H48 (20.9 \pm 2.3 vs. $36 \pm 3.67 \mathrm{~mm} \mathrm{Hg}, \mathrm{p}=0.001$ ), as shown in figure $2 \mathrm{~b}$. However, no differences were observed in MPAP values between baseline and T1, T2, and T3 H168. Mean values and standard deviation for both groups at each time point are presented in table 2 . We observed a positive correlation between MPAP and PVR at H48 ( $\mathrm{r}=0.93 ; \mathrm{p}=0.024)$.

No differences were observed between PAOP values at any time points (fig. 2c).

\section{Histology}

Reference samples of left upper lobe tissue showed insignificant inflammatory infiltration and no interstitial edema or alveolar overdistension. There was no difference between peripheral and central lung tissue samples, and pulmonary damage was equally distributed within each lobe at all time points. No signs of alveolar overdistension were observed in the left lung at T2 or in the right lung at T3 H48 and T3 H168.

In the remaining right lung, only PDS regarding inflammatory infiltration and no interstitial edema were significantly modified. Mean PDS for interstitial edema was increased at H48 [4.6 \pm 1.4 (3-6), p = 0.007; fig. 3a] and remained stable at H168 [4.4 \pm 2.7 (1-7)]. Similarly, PDS for inflammatory infiltration score was increased at both $\mathrm{H} 48$ [5.2 \pm 2.3 (3-9)] and H168 [6.8 \pm 2.1 (4-9), $\mathrm{p}=0.007]$.

We observed a positive correlation between MPAP and interstitial edema $(r=0.65 ; p<$ $0.05)$ and between PVR and interstitial edema ( $r=0.79 ; \mathrm{p}<0.05)$ after left pneumonectomy, but no significant relationship between inflammatory infiltration and pulmonary hemodynamic data (MPAP and PVR) after pneumonectomy (fig. 3b).

\section{BAL Albumin Level}

The reference concentration at T0 showed insignificant BAL (fig. 4). At T3 H48, mean BAL increased significantly compared to T0 and T2 ( $\mathrm{p}=0.02)$; no difference was observed between T3 H48 and T3 H168. We observed a significant correlation between BAL and MPAP $(r=0.55 ; p=0.02)$, but not between BAL and PDS for inflammatory infiltration or interstitial edema. 

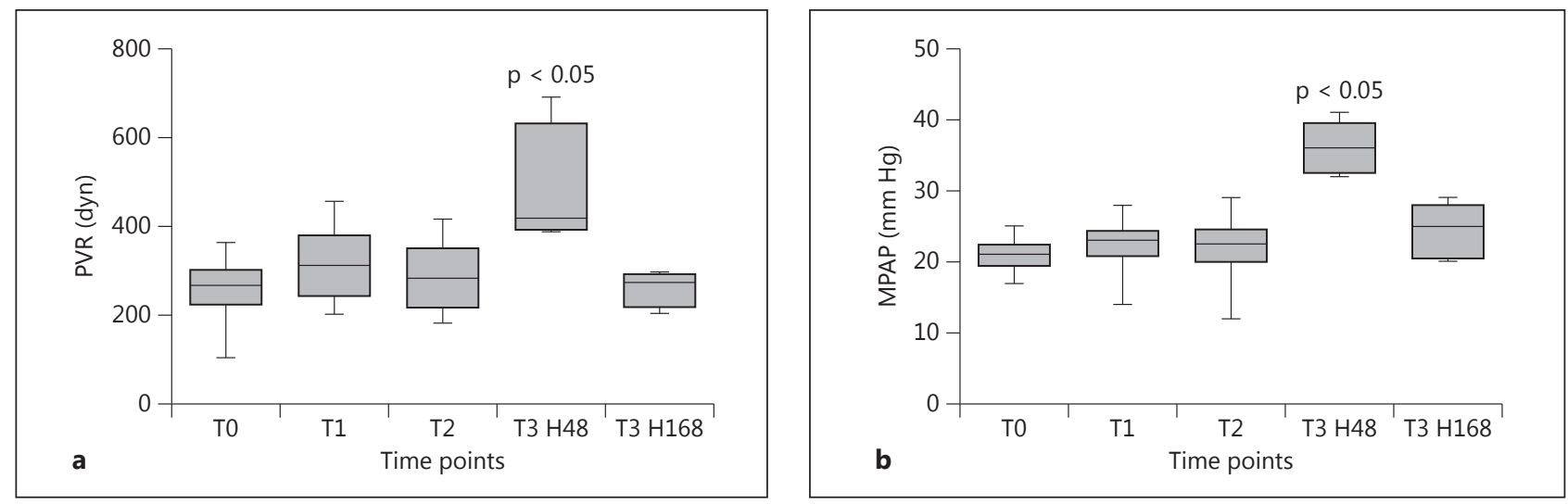

Fig. 2. Pulmonary hemodynamics at different time points. a PVR. b MPAP. c PAOP.

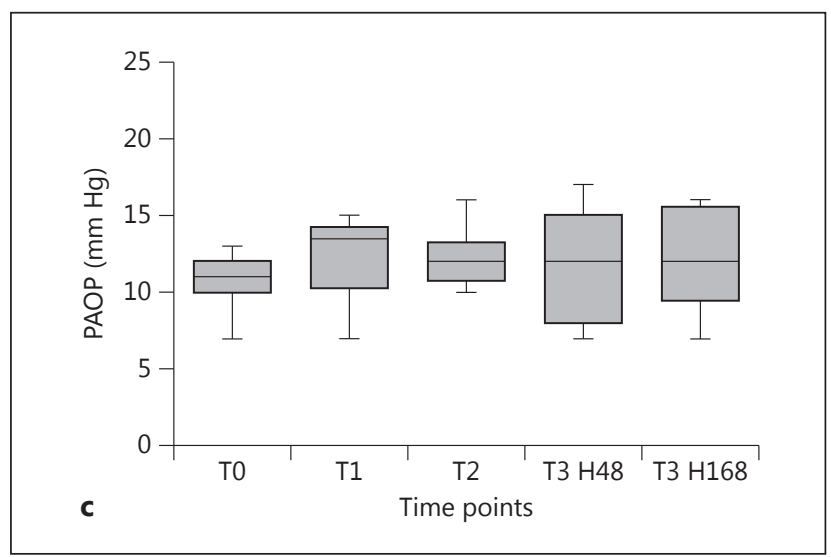

\section{Discussion}

PPE induction by MPR could be considered an unintended intersection of preoperative mechanisms exacerbated by perioperative fluid overload $[6,19]$. Several factors may be involved in the occurrence of PPE: (a) immediate overflow into the remaining pulmonary artery combined with increased endothelial permeability [7, 9]; (b) impairment of lymphatic pump capacity [6, 7], and (c) mechanical side effect of OLV [15], although their respective roles are still debated [5].

In order to focus on blood overflow impact, we eliminated most of the controllable interpretive bias. We precluded the ischemia-reperfusion phenomenon by performing pneumonectomy only, hyperoxia by limiting $\mathrm{FiO}_{2}$, excessive electrolyte filling by limiting fluid load, and mechanical ventilation side effects by using low $V_{t}$. Finally, no lymphadenectomy was done, eliminating the consequences of that procedure. This study assessed immediate and mid-term hemodynamic consequences of MPR, in conjunction with a histological analysis of lesions occurring in the remaining lung, when resection is performed with protective ventilation.

Our main finding is that MPR induces a transient increase in MPAP $(44.8 \pm 16 \%)$ and PVR $(52.5 \pm 23 \%)$, which did not occur immediately after the arterial cross-clamping but was correlated with interstitial edema. PAOP was low and rise of MPAP at H48 was correlated with PVR values, evidencing a delayed temporary precapillary pulmonary artery hypertension after MPR. Considering that pulmonary artery hypertension is precapillary, we confirmed that edema induced by MPR occurs secondary to a lesional mechanism and 


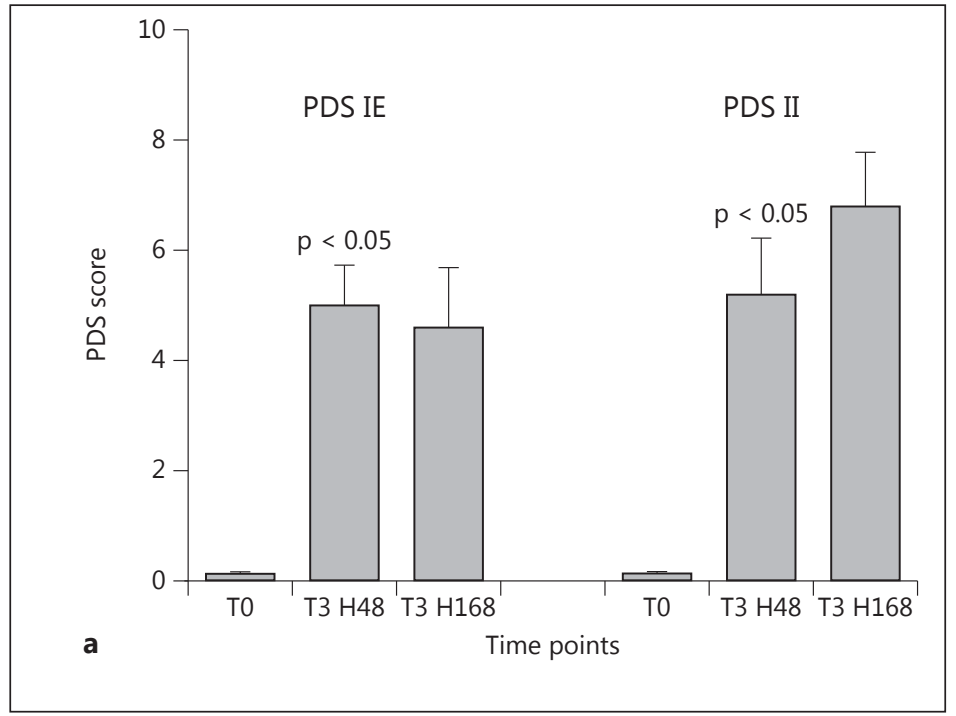

Fig. 3. a PDS regarding interstitial edema and inflammatory infiltration. b Correlation between PDS (interstitial edema) and MPAP. IE = Interstitial edema; II = inflammatory infiltration.

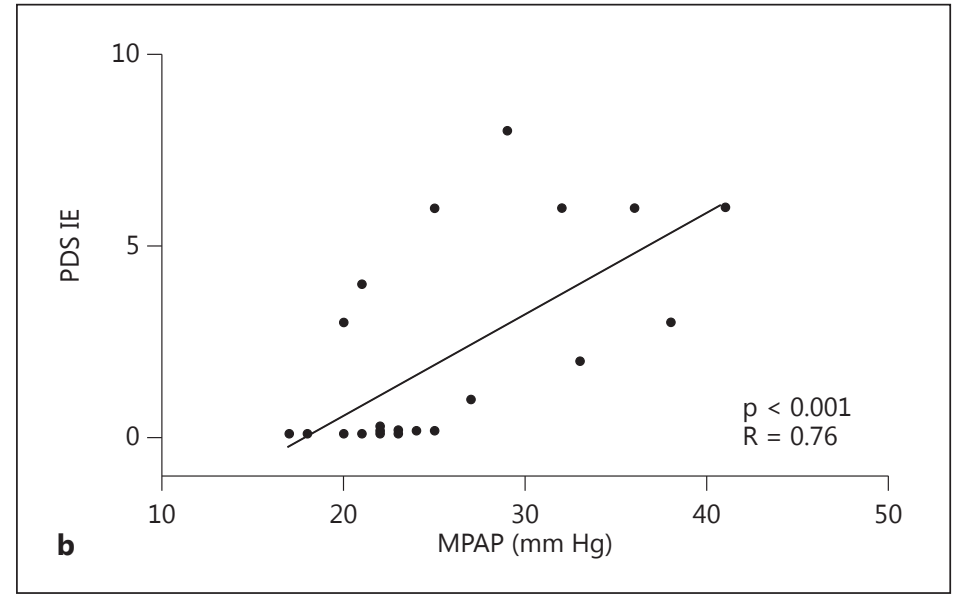

confirmed previous speculations that postoperative pulmonary artery hypertension is correlated with the risk of developing PPE [7].

Pulmonary vascular networks may greatly expand to allow a major increase of lung capillary flow during an incremental effort test [20]. Just after cross-clamping the arterial supply of the lung to be resected, the entire right heart flow suddenly moves through a single remaining artery, inducing an initial overflow. We observed MPAP stability during at least $2 \mathrm{~h}$ after pulmonary artery cross-clamping, without any changes in cardiac output, PVR, and PAOP. Thus, the vascular network successfully expanded to face the initial overflow, with vasodilatation or recruitment of quiescent capillaries. We observed a positive correlation between MPAP and interstitial edema at $\mathrm{H} 48$, which could be considered as the initial phase of PPE. Thus, the previously reported delayed onset of clinical PPE (48-72 h) after pneumonectomy $[1,5,21]$ could be related to the initial vascular capacitance adaptation observed in our study. This pulmonary hemodynamic profile has never before been reported, probably because of more aggressive mechanical ventilation parameters and electrolyte filling used in previous studies $[22,23]$.

In a review describing the potential etiologic factors of PPE, Park [19] hypothesized that interstitial edema is a consequence of increased pulmonary vascular permeability at the 
Fig. 4. BAL albumin level. Correlation between BAL albumin level and MPAP after left pneumonectomy.

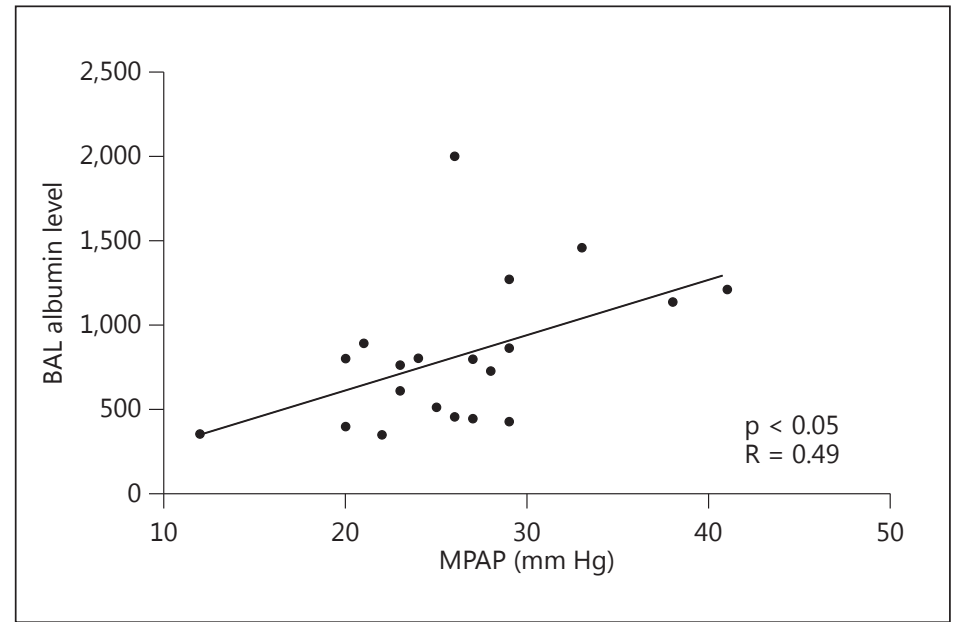

capillary and arteriolar levels, subsequent to hypoxic endothelial cell damage. In our study, increases in PVR at T3 H48 were very similar to the characteristics of hypoxic pulmonary vasoconstriction $[7,21]$ which is regulated by modification of the level of endothelial-derived vasoactive substances $[12,24]$. However, hypoxic pulmonary vasoconstriction does not seem to predominate in our study because our pigs maintained a constantly high venous oxygen saturation $\left(\mathrm{SvO}_{2}\right)$ level. After MPR, initial overflow into the remaining pulmonary artery induces modifications in frictional force of blood flow [12]. These mechanical constraints are known to modify circulating endothelial-derived vasoactive substances inducing vasodilatation [12]. In contrast, when these mechanical constraints are maintained for a long time at a high level (prolonged strenuous exercises), they may participate in delayed PVR increase due to vasodilatation mechanism exhaustion [25].

Previous studies assessed pulmonary endothelial intercellular junction disruption [26] or loss of integrity of the proteoglycan components of the interstitial space [7] immediately after overflow, followed by rapid $(12 \mathrm{~h})$ endothelial cell remodeling and reestablishment of cell junction [27]. In our study, precapillary pulmonary hypertension correlated with interstitial edema at $\mathrm{H} 48$, indicating that delayed endothelium injury may be mainly caused by overflow. Precapillary pulmonary hypertension also correlated with BAL, which has been used as a surrogate marker of alveolar-capillary barrier dysfunction usually concurrent with local inflammation [27]. The rise of BAL at $\mathrm{H} 48$ confirms that edema formation was due to an increase in vascular permeability rather than in vascular filtration pressure [7]. This is not consistent with a previous suggestion [15] that increased blood flow is insufficient to explain interstitial edema after MPR and that alveolar-capillary membrane disruption induced by high $V_{t}$ is the main responsible factor. Indeed, as evidenced by the lack of alveolar hyperinflation in our study, pulmonary artery hypertension, interstitial edema, and inflammatory infiltration were observed despite protective OLV. Local inflammation was a full-fledged phenomenon, persisting 7 days after pneumonectomy despite protective intraoperative ventilation; evolution was not correlated with pulmonary hemodynamics, but may also participate in lesional edema [1].

Altogether, our results indicate that the pulmonary vascular network's ability to expand when challenged by a sudden increase of flow could be a major parameter in explaining the variable appearance of PPE. Moreover, any pharmacological tool that increases the capacitance of the pulmonary vascular network seems promising for PPE prevention. Although intraoperative nitric oxide inhalation seems to be a good candidate, its ineffectiveness in 
avoiding interstitial pulmonary edema has been highlighted [22]. Considering that PVR increase was observed to be delayed in our study, pharmacological treatment holds promise when focusing specifically on a late increase in pulmonary capacitance.

In our study, the pigs experienced a minor form of PPE and none progressed to acute respiratory distress syndrome with $\mathrm{PaO}_{2} / \mathrm{FiO}_{2}<200$. The lack of initial aggression on the alveolar-capillary barrier (due to implementation of a protective OLV) and a progressive shift towards a new hemodynamic equilibrium after H48 (evidenced by decreases in MPAP and increased cardiac output at T3 H168) related to high vascular network compliance in young nondiseased pigs are potential explanations. This high vascular compliance may be considered as a limitation of this study to implement the results in humans; however, the study did not fail to assess pulmonary hemodynamic deterioration after MPR.

Only 4-15\% of patients undergoing MPR will present PPE during their postoperative course. This study helps to explain the occurrence of PPE in at-risk patients despite a modern regimen of protective ventilation. A pneumonectomy (especially of the right lung) or a previous history of pulmonary resection are responsible for a major amputation of the pulmonary vascular network and thus impaired vascular reserve adjustment.

\section{Acknowledgements}

We acknowledge Elaine M. Lilly, PhD, for her experienced contribution to the English language editing of this manuscript and Hubert Taillade for his experienced contribution in animal care.

\section{References}

1 Licker M, de Perrot M, Spiliopoulos A, Robert J, Diaper J, Chevalley C, Tschopp JM: Risk factors for acute lung injury after thoracic surgery for lung cancer. Anesth Analg 2003;97:1558-1565.

2 Tang SS, Redmond K, Griffiths M, Ladas G, Goldstraw P, Dusmet M: The mortality from acute respiratory distress syndrome after pulmonary resection is reduced: a 10 year single lung institutional experience. Eur J Cardiothorac Surg 2008;34:898-902.

3 Kutlu CA, Williams EA, Evans TW, Pastorino U, Goldstraw P: Acute lung injury and acute respiratory distress syndrome after pulmonary resection. Ann Thorac Surg 2000;69:376-380.

4 Slinger PD: Perioperative fluid management for thoracic surgery: the puzzle of postpneumonectomy pulmonary edema. J Cardiothorac Vasc Anesth 1995;9:442-451.

5 Zeldin RA, Normandin D, Landtwing D, Peters RM: Postpneumonectomy pulmonary edema.JThorac Cardiovasc Surg 1984;87:359-365.

6 Zairns CK, Rice CL, Peters RM, Virgilio RW: Lymph and pulmonary response to isobaric reduction in plasma oncotic pressure in baboons. Circ Res 1978;43:925-930.

7 Miserocchi G: Mechanisms controlling the volume of pleural fluid and extravascular lung water. Eur Respir Rev 2009;18:244-252.

8 Reed CE, Spinale FG, Crawford FA: Effect of pulmonary resection on right ventricular function. Ann Thorac Surg 1992;53:578-582.

9 West JB, Mathieu-Costello 0: Stress failure of pulmonary capillaries, role in lung and heart disease. Lancet 1992;340:762-767.

10 Turnage WS, Lunn JJ: Postpneumonectomy pulmonary edema. A retrospective analysis of associated variables. Chest 1993;103:1646-1650.

11 Williams DA: Network assessment of capillary hydraulic conductivity after abrupt changes in fluid shear stress. Microvasc Res 1999;57:107-117.

12 Li YS, Haga JH, Chien S: Molecular basis of the effects of shear stress on vascular endothelial cells. J Biomech 2005;38:1949-1971.

13 Maxey TS, Fernandez LG, Reece TB, Keeling WB, Kron IL, Laubach VE: Endothelial nitric oxide synthase is essential for postpneumonectomy compensatory vasodilation. Ann Thorac Surg 2006;81:1234-1238.

14 Van der Werff YD, van der Houwen HK, Heijmans PJ, Duurkens VA, Leusink HA, van Heesewijk HP, de Boer A: Postpneumonectomy pulmonary edema. A retrospective analysis of incidence and possible risk factors. Chest 1997;111:1278-1284.

15 de Prost N, Ricard JD, Saumon G, Dreyfuss D: Ventilator-induced lung injury: historical perspectives and clinical implications. Ann Intensive Care 2011;1:28. 
16 Schmitt JM, Vieillard-Baron A, Augarde R, Prin S, Page B, Jardin F: Positive end-expiratory pressure titration in acute respiratory distress syndrome patients: impact on right ventricular outflow impedance evaluated by pulmonary artery Doppler flow velocity measurements. Crit Care Med 2001;29:1154-1158.

17 Jaber S, Sebbane M, Koechlin C, Hayot M, Capdevila X, Eledjam JJ, Prefaut C, Ramonatxo M, Matecki S: Effects of short vs prolonged mechanical ventilation on antioxidant systems in piglet diaphragm. Intensive Care Med 2005;31:1427-1433.

18 Quintel M, Heine M, Hirschl RB, Tillmanns R, Wessendorf V: Effects of partial liquid ventilation on lung injury in a model of acute respiratory failure: a histologic and morphometric analysis. Crit Care Med 1998;26:833843.

19 Park BJ: Respiratory failure following pulmonary resection. Semin Thorac Cardiovasc Surg 2007;19:374-379.

20 Bougaci N, Costes F, Bertoletti L: Non-invasive study of pulmonary vascular recruitment during exercise. Rev Pneumol Clin 2010;66:173-178.

21 Dumas JP, Bardou M, Goirand F, et al: Hypoxic pulmonary vasoconstriction. Gen Pharmacol 1999;33:289-297.

22 Roch A, Michelet P, D'Journo B, Brousse D, Blayac D, Lambert D, Auffray JP: Accuracy and limits of transpulmonary dilution methods in estimating extravascular lung water after pneumonectomy. Chest 2005; 128:927933.

23 Filaire M, Fadel E, Decante B, Seccatore F, Mazmanian GM, Hervé P: Inhaled nitric oxide does not prevent postpneumonectomy pulmonary edema in pigs. J Thorac Cardiovasc Surg 2007;133:770-774.

24 Dantzker DR, Brook CJ, Dehart P, et al: Ventilation-perfusion distributions in the adult respiratory distress syndrome. Am Rev Respir Dis 1979;120:1039-1052.

25 Ricciardolo FL, Sterk PJ, Gaston B, Folkerts G: Nitric oxide in health and disease of the respiratory system. Physiol Rev 2004;84:731-765.

26 Fu Z, Costello ML, Tsukimoto K, et al: High lung volume increases stress failure in pulmonary capillaries. J Appl Physiol 1992; 73:123-133.

27 Ward C, Walters EH, Zheng L, Whitford H, Williams TJ, Snell GI: Increased soluble CD14 in bronchoalveolar lavage fluid of stable lung transplant recipients. Eur Respir J 2002;19:472-478. 